\title{
Mental readiness: focusing on the cutting edge
}

McLaughlin Centre for

Population Health Risk

Assessment, Faculté de médecine/Faculty of Medicine, Universite d'Ottawa/University of Ottawa

To whom correspondence should be addressed: Judy M McDonald

e-mail:

judy.mcdonald@uottawa.ca

Available at:

http://www.archpedneurosurg.com.br/
Judy M McDonald

Several intriguing questions were raised during my presentation on Mental readiness and pediatric neurosurgery at the Brazil Society for Pediatric Neurosurgery (BSPN) Scientific Meeting-Webinar on April 15,2020 . Does arrogance disturb mental readiness techniques? Can mindfulness techniques improve surgical readiness? Can simulation models improve mindfulness? How do you stay focused on routine procedures you've done 800 times? The University of Ottawa (Canada)-where I am a research scientist in at the McLaughlin Centre for Population Health Risk Assessment in the Faculty of Medicine-has conducted extensive studies on a new discipline called operational readiness. It correlates research with the performances of Olympic athletes and people in high-risk occupations, like surgeons, air traffic controllers and police, whose standards of excellence have life-and-death consequences. So, what can we learn from the best in these fields? Plenty. Our ongoing work makes it clear that effective focusing practices impact one's performance. But, it is not always easy to "be there for the task-athand with all your attention on the right things for the duration of the event without distracting thoughts." Here are five focusing techniques used by elite surgeons and other peak performers compiled by researchers at the University of Ottawa.

Keyworks: Mental readiness, Pediatric neurosurgery, Full focus,

\section{EXPECT TO EXPERIENCE TOTAL CONCENTRATION}

Have you been so focused that you experience a heighten awareness of your senses while you are performing surgery? You are concentrating on what you are doing, seeing, hearing, reading, feeling, learning, smelling or observing while you are engaged in every step. One neurosurgeon described it as a sequence of layers.

Once I actually start the surgery, I focus on each step of the surgery. As I actually make the skin incision, I'm focusing, concentrating on the layers below the skin. Each step has its own focus.
You may get so completely focused that you don't eat, drink or even go to the bathroom for seven or eight hours. Even migraine sufferers say that in a challenging surgery in the middle of a migraine crisis - the migraine disappears! But in a regular case, the migraine will linger because there is time to think about the headache.

Some surgeons create rituals to set the tone (for everyone) and take care of the little things like: eliminating distractions, putting their back to the door, turning down the peripheral lights, turning on Mozart and then, the ECG beeps disappear. Refining rituals that have inspired your best performances will make successes more frequent. 


\section{Mental readiness: focusing on the cutting edge}

Genetics can also influence your ideal focus-most of us are either naturally morning people or night people-which means you should work with what you've got to achieve your personal best. To optimize your natural inclinations, be consistent. Align challenging surgeries with your internal clock. Allocate enough time for both the surgery and winding up or down to be able to focus.

\section{HONE YOUR EMOTIONAL CONTROL AND POSITIVITY}

Emotional well-being, regardless of your personality profile, is critical if you want to be fully focused. Elite performers learn that emotional control is essential and that doesn't mean shoving things under the rug. Disappointments must be resolved to clear consciences and prepare the mind and the body for the next surgery. One strategy to achieve that is being honest and open. "If you're honest with yourself and honest with your patients," one surgeon told me, "you can function because you have a clear conscience. That helps a lot in putting up with the stress."

Next, your performance stands to gain if you are simply friendly-to your family, your colleagues, your team, the patient and the hospital administration.

It's a matter of total concentration and not allowing emotion to enter into it. During routine operations, it's wise to try to keep the atmosphere as relaxed as you can, especially with young trainees, to reassure them that you are supportive. Be friendly with them to inspire confidence. If they happen to go a little astray, you bring them back gently so there won't be a crisis.

Most of the time, being in the OR should be absent of anxiety, free of internal and external interferences-like a pleasant, relaxing experience or quiet white noise. With a wall in front, real or imagined, use this time to scrub-up, psyche-up and focus. Make it your time to control your emotional volume and direction to what works best for you. For these surgeons, the OR is like an oasis.

It's stressful but at the same time it's fun. Sure, it is! When I've had a successful surgery, I was usually feeling good. I think that makes a difference. You know when sometimes you don't feel right? It's not fun. If it's not fun, then it's difficult.

Having a dark room with the focus of light just on the patient's head or spinal cord where you're working is most relaxing. It's wonderful! I could be there all day.

When you can direct your emotions in a positive way, your ability to anticipate is also amplified. Your critical thinking can go beyond 'being in the moment' to the next step and the unexpected.
I like to constantly be thinking ahead-'What am I going to be doing after this procedure? What should I be telling the scrub nurse to get ready? What problems might we encounter after this stage?'

You've got to be totally focused, remembering each step, seeing all the steps going through your mind, and taking them all down to their end point.

\section{PLAN FOR THE 'MUNDANE'}

It may seem counterintuitive, but maintaining alertness during low-workload periods requires considerable mental stamina and can cause even more fatigue. Air-traffic-control studies were examined for human attentiveness in air-traffic incidents. For instance, it was shown that operational errors occur most frequently during conditions of low rather than high traffic. It is referred to as a lack of situational awareness and attention vigilance (Edwardsa et al, 2012). Similarly, 80 percent of incidents in high-altitude climbing occur not on the ascent but on the descent (...starting with photo ops at the summit when climbers' guard is down; McDonald et al, 2015).

In a police study (McDonald, 2006) looking at performance excellence, repeated false-alarms from the same apartment were described as monotonous by most officers. However, what emerged was that 11 of the 48 'excellent' officers interviewed did not report this feeling of complacency on such mundane calls. What did they have in common? They had either been shot or their partner had been shot-and they were NOT going to let it happen again. Scenarios with actors and Table-Top Exercises (TTXs) are frequently used in policing to mimic various encounters (including the mundane). Officers experience close to the 'real thing,' followed by an immediate debrief where the officers and observers assess: What went well? What did not go well? What could be done differently?

Of all the distractions in surgery, the one rated by almost all surgeons (94\%) was the danger of drifting during uninteresting or routine situations. And yet the ability to get back on track after straying from the task was the least common distraction-control skill (McDonald et al, 1995). Incidents described as causing a surgeon to drift were: delays, 'routine' or frequently performed surgeries, closing after a successful procedure, extra lengthy operations, assisting and watching surgery.

You're really eager to get going-that's why you put those cases at 8:00 in the morning. If they tell you, 'You're going to be delayed' then that really throws you off. 


\section{Mental readiness: focusing on the cutting edge}

I find that my mind does wander when I'm assisting on a big, long, long operation. I think about other things that are not medically related.

My big problem is that I can't watch surgery very well. It's hard to sit on the bench. I find it hard to keep my concentration, especially if a resident is there with a fellow who I know is competent. I need to do the surgery. This is difficult in a teaching program. It's one of my failings.

In operations of lesser magnitude, your mind can wander. You remember last night's game, you think about what you're going to be doing on the weekend because the operation is not stressful. It's easy compared to major operations, where you think only of what's happening.

Among the best surgeons, some were comfortable with a lack of focus in certain situations and others found any drifting unacceptable.

At crunch time, you have to be able to exclude other things from your mind. As soon as you've overcome the difficult part of the surgery, then I say, 'Joke, laugh, relax, sit down or whatever'-but you've got to be ready. Like at the starting of a race, you have to have everything focused purely on the procedure.

I don't like drifting because you can miss things... It's the successful endings that you drift. You think, 'What could happen? I'm just closing. It's a very simple thing.' That's when drifting can happen.

Skill development for dealing with passive distractions need to be addressed and customized to the individual surgeon such as: learning to relax, shifting tasks, thinking positively, persisting, slowing down and/or being reminded that every operation could be "the big one!"

You do drift. That's human nature but that's when the risk factor increases. You have to realize your attention span. It's decent the first hour or two, but after four hours it gradually lessens. As the operation gets lengthy, you have to be careful that you don't start losing your patience. When you want to finish, you have to tell yourself, 'No, you should not rush. Take your time or you'll get into trouble.'... You say, 'Slow down! It's better for the patient and for me in the long run-it will save me time and stress.'... At the end of an operation, you do not want trouble. That's when you want things to go smooth, so that you can finish, close and go home. Knowing these things does help you in preparing during those moments.

When you feel too ready for things, they become boring because there is no challenge left to them. I feel I'm always a student as I go along... I feel ready competent-wise in handling it and I am prepared to do it but I don't feel ready in that everything's going to be guaranteed to go smoothly. Once you stop learning, you should stop operating.

\section{FIND EASE AND RHYTHM THROUGH MINDFULNESS}

Being "in the zone" is like auto-pilot that lets things unfold naturally. You feel totally connected to trust yourself and your training. You find your rhythm and notice the changes in tempo, demands in effort and flows in movement. Sometimes the surgery may even take on a rhythm of its own where it feels very connected. Having situational awareness in the 'here and now' means:

- connecting to relevant cues to execute the immediate task-at-hand

- $\quad$ feeling an economy of movement

- taking "mental time outs" during breaks in the action or when you are out of the OR

- $\quad$ changing your expectations and mindset when you are a more passive participant

- $\quad$ staying positive to sustain alertness and persistence during long or routine surgeries

If unwanted stress is preventing this feeling of ease, mindfulness meditation is one of the most effective means to relax. This skill of remaining "in the moment" has become a worldwide phenomenon in professional sports. As one European national tennis champion confided: "I used to freeze up whenever I made a mistake-not sure I deserved to play at this level. Now when I blow a serve or shank a backhand, I still get those flashes of self-doubt, but I know how to handle them: I acknowledge the negative thoughts and let them slide by, focusing on the moment."

Be warned that "mindfulness" can turn into what Ronald Purser (2019) refers to as 'McMindfulness'-new rage, 'commercialization,' 'quick fix' mindfulness-the McDonaldization of feeling good then an hour later still being hungry. While a monk, neurobiologist or life coach are not necessary, some sources of guidance you may find inspirational are:

If you are facing in the right direction, all you need to do is keep on walking-Buddha.

The best way to capture moments is to pay attention. This is how we cultivate mindfulness-Professor Jon Kabat-Zinn, University of Massachusetts Medical School and creator of the Center for Mindfulness in Medicine. 


\section{Mental readiness: focusing on the cutting edge}

Mindfulness isn't difficult, we just need to remember to do it-Sharon Salzberg, World-renowned meditation teacher and NY Times bestselling author.

How you look at it is pretty much how you'll see itRasheed Ogunlaru, Leading life-leadership coach, motivational speaker and author.

Do every act of your life as though it were the very last act of your life-Marcus Aurelius, Philosopher and Emperor of Ancient Rome, 2nd century

If sitting still with your eyes closed is not your style, other relaxation techniques emphasize paying attention to the present moment. An easy way to start is to take a breath and simply commit to being aware of the present moment. Slow, deep breathing sends calming signals to the brain, which in turn can slow heart rate and nervous activity. Breathing exercises, particularly when performed ritualistically, can sharpen focus and aid in handling conflict and building team relationships under pressure. Alternatively, one surgeon said when he felt anxious, he put his hands together, stood still and briefly reassessed before taking action again.

When surgery is very lengthy, with many fluctuations in tempo, surgeons need to flow between intense and more relaxed moments. It's important to remain alert to relevant cues but not necessarily fully engaged. Recognizing that slow, routine periods demand a different type of mental control is vital for long-term success.

Economy of movement is the most important thing in good surgery. Do everything right the first time. If you've got to go back in to do something, you're going to have many more problems. Don't rush through just because time is going by. Just carry on. No matter what, just take your time and do it right.

If I'm doing a procedure that takes a lot of attention, I tend to be very focused. I don't see or hear anything that goes on around me-everything gets shut out. That's how I can tell when I am focused. If my concentration is going in and out because it doesn't have to be in, I can chat with the nurses or my assistant while still paying attention.

I use music and I talk to people. I don't leave the OR. I don't stop the operation. I just continue working. I stay there all the time. Usually, I don't drink or eat or do anything. I just go on and on until I finish. If there is an assistant that wants to go out, then fine, they can go out. They can drink or whatever, but I keep on going. I don't like to stop... I'd get too relaxed.

What you didn't plan for was how tedious it was going to be when you got down there... After about an hour you say, 'Holy schmoly, I'm going to be in here for a day. Maybe we made a bad decision in going ahead with this and should have planned this in stages.' You go through second thoughts even though you're already well on your way in the operation. You discipline yourself to just go at it and to NOT start taking short cuts to try to hurry it along a little bit. Usually, if you just remain meticulous, stick to your guns and the basic strategy you've developed, you'll find that it all works out in the long run. Then you feel really good about it... Your resident or your assistants are also having second thoughts throughout the whole case saying, 'Why the hell are we here? Is this ever going to finish? Why doesn't the silly bugger stop, get out and come back another day?' Then all of a sudden, 'Geez, it's all over and done. Yeah, that wasn't so bad. Good thing we stuck to it and just went on with it.'

\section{RECHARGE, PERFORM BETTER OR HAVE A PLAN B}

Feeling mentally ready is linked to your physical and technical readiness. For example, the quality of your focus can be influenced by your eating and resting habits.

Perhaps strategic eating is your answer. Where a big heavy meal can make concentration so much harder (nap time anyone?), a light, easy to digest meal can make you feel fit, confident and prepared to tackle any challenge.

"The old-school approach of toughing it out is counterproductive," argues Charles Czeisler, director of the division of sleep medicine at Harvard Medical School, a consultant to NASA and the Secret Service. He maintains that sleep deprivation influences not only mental but also physical health and performance under pressure. Sleep helps build long-term memories, and fully incorporating the day's lessons requires a full sleep. In safety-sensitive environments, sleep is part of "operational fatigue risk management." Bill Gates shared that he used to work through the night, relying on midday naps for rest, but realized that he couldn't enjoy a high quality of life that way: "I like to get seven hours of sleep a night because that's what I need to stay sharp and creative and upbeat" (Beck, 2009).

Good work-life balance to feel rested sometimes means you have to take a break. Do something unrelated that will clear your mental and physical state-just to get recharged. Days off are significant for recovery, especially with shift work, you have to refresh yourself. Know your body during times when you work weeks straight, no days off. Know that if you keep pushing, pushing, pushing, you'll break down. Intuitive as this may be, there's also strong evidence that anxiety and depression can both cause fatigue, and vice versa, fatigue and insomnia are strongly associated with depression and other mood disorders.

Can you rest anywhere? Experts are mixed on the benefits of napping, cautioning that catching up on sleep 


\section{Mental readiness: focusing on the cutting edge}

through micro-rests doesn't cut it. Napping is a survival technique or recovery strategy limited to $\mathbf{3 0}$ minutes, not a replacement for quality sleep. Even a quick break to relax can restore energy, aid in anticipating the next step and renew a positive perspective (McDonald, 2020).

Here's some irony: for peak performers, long work-days and interrupted sleep patterns are frequently standard occupational hazards. While it's not ideal, it happens. And when it does, the pros have insight into how to stay on your game when you're exhausted - when you're beat, have a Plan B! In surgery when your concentration is interrupted, it is more difficult to be alert, relaxed and meticulous. "If I've been up all night, it makes everything more painful," a surgeon told me, "It affects some of the more mundane aspects of the operation, and you need to bring a back-upusually I have somebody senior scrub in with me. Or sometimes I step out for a little while, take a break and come back in." When fatigued, police also find strength in numbers. "Even when I'm tired, I don't want to lose to bad people," one officer says. "Call me chicken, but I'm going to bring some friends with me."

\section{REFERENCES}

Beck H. Bowing to body clocks, NBA teams sleep in. The New York Times. 2009 Dec 20:SP1.

Edwards T, Sharples S, Wilson JR, Kirwan B. Factor interaction influences on human performance in air traffic control: The need for a multifactorial model. Work. 2012 Jan 1;41(Supplement 1):159-66.
McDonald JM. Gold medal policing: Mental readiness and performance excellence. New York, NY: Sloan Associate Press; 2006.

McDonald J, Dahal G, Tyshenko M, Sloan D, Sharma S. Operational readiness: Links to Sherpas' peak performance in tourist mountain-guiding. In Sustainable livelihood systems in Nepal (pp. 281-308). Kathmandu, Nepal: International Union for Conservation of Nature, Nepal Country Office (IUCN Nepal), 2015.

McDonald J, Orlick T, Letts $M$. Mental readiness in surgeons and its links to performance excellence in surgery. Journal of pediatric orthopedics. 1995 Sep 1;15(5):691-7.

McDonald J, Orlick T. Excellence in surgery: psychological considerations. Contemporary Thought on Performance Enhancement. 1994;3(1):13-22.

McDonald, J. Sleep like a pro, In Special Edition: The science of sleep (pp. 40-45), Time Inc. Books, 2020, 96 pages.

Purser R. McMindfulness: How mindfulness became the new capitalist spirituality. Repeater; 2019 Jul 9. 